\title{
Revealing changes in molecular composition of plant cell walls on the micron-level by Raman mapping and vertex component analysis (VCA)
}

\author{
Notburga Gierlinger ${ }^{1,2,3}$ * \\ ${ }^{1}$ Department of Materials Science and Process Engineering, BOKU-University of Natural Resources and Life Science, Vienna, Austria \\ 2 Institute for Building Materials, Eidgenössische Technische Hochschule Zurich, Zurich, Switzerland \\ ${ }^{3}$ Applied Wood Research Laboratory, Empa - Swiss Federal Laboratories for Material Testing and Research, Duebendorf, Switzerland
}

\section{Edited by:}

Andreia Michelle Smith-Moritz, Lawrence Berkeley Labs, USA

\section{Reviewed by:}

Dina M. Bower, Carnegie Institution of Washington, USA

Gordon Graham Allison, Aberystwyth University, UK

\section{*Correspondence:}

Notburga Gierlinger, Department of Materials Science and Process Engineering, BOKU-University of Natural Resources and Life Science, Peter-Jordan Street 82, A-1190 Vienna, Austria

e-mail: burgi.gierlinger@boku.ac.at
At the molecular level the plant cell walls consist of a few nanometer thick semi-crystalline cellulose fibrils embedded in amorphous matrix polymers such as pectins, hemicelluloses, and lignins. The arrangement of these molecules within the cell wall in different plant tissues, cells and cell wall layers is of crucial importance for a better understanding and thus optimized utilization of plant biomass. During the last years Confocal Raman microscopy evolved as a powerful method in plant science by revealing the different molecules in context with the microstructure. In this study two-dimensional spectral maps have been acquired of micro-cross-sections of spruce (softwood) and beech (hardwood). Raman images have been derived by using univariate (band integration, height ratios) and multivariate methods [vertex component analysis (VCA)]. While univariate analysis only visualizes changes in selected band heights or areas, VCA separates anatomical regions and cell wall layers with the most different molecular structures. Beside visualization of the distinguished regions and features the underlying molecular structure can be derived based on the endmember spectra. VCA revealed that the lumen sided S3 layer has a similar molecular composition as the pit membrane, both revealing a clear change in lignin composition compared to all other cell wall regions. Within the S2 layer a lamellar structure was visualized, which was elucidated to derive from slight changes in lignin composition and content and might be due to successive but not uniform lignification during growth.

Keywords: secondary cell wall, wood, lignin, cellulose, beech, spruce, Raman microscopy, VCA

\section{INTRODUCTION}

Plant cell walls comprise very complex and highly variable structures. Their basic structural elements are crystalline cellulose [(1-4)- $\beta$-linked glucose] microfibrils embedded in matrix polymers. In the thin primary cell wall $(0.1-1 \mu \mathrm{m})$ built during early growth a network is formed together with pectins, hemicelluloses, and proteins (Keegstra, 2010). These thin walls give already shape and structure to plant cells, tissues, and ultimately organs and are sufficiently strong to prevent the cell from rupturing, yet they must be flexible and plastic to accommodate growth (Cosgrove, 2005). The secondary cell wall, a thick layer which is deposited after cells cease enlargement, is often lignified. The deposition of lignin in the plant cell wall has been considered to be one of the key factors that allowed land plants to flourish in terrestrial ecosystems (Weng and Chapple, 2010). Lignins are three-dimensional, amorphous heteropolymers that result from the oxidative coupling of three $p$-hydroxycinnamyl alcohols ( $p$-coumaryl, coniferyl, and sinapyl alcohols) in a reaction mediated by roughly ten enzymes leading to the formation of guaiacyl (G), syringyl (S), and hydroxyphenyl (H) subunits (Boerjan et al., 2003). The cross-coupling reaction produces an hydrophobic heteropolymer, that imparts water impermeability and confers structural support and flexural stiffness to the plant cell wall (Vanholme et al., 2010). The nature and randomness of the linkages make lignin to one of the hardest biopolymers to degrade (Ralph et al., 1998). The amount and molecular structure of the lignin in the cell walls is indeed one of the limiting factors that determine the digestibility of forage crops (Bhatt et al., 2008; Studer etal., 2011; Yoo et al., 2012). Lignins are therefore an undesirable component not only in the pulp industry, but also in the biofuel production (Ralph et al., 2004; Pu et al., 2011; Yoo et al., 2012; Kim and Ralph, 2014). Given the advances in biotechnology and genetics, it is only natural that these tools are explored to improve the desired feedstock properties, e.g., enhance the biological conversion properties of lignocellulosic crops ( $\mathrm{Lu}$ et al., 2009). Downregulating the enzymes of the major lignin pathways can affect the course and/or extent of lignification and gives expanded opportunities for engineering the composition and consequent properties of lignin for improved utilization of valuable plant resources (Boerjan et al., 2003; Artz et al., 2008; Gonzalez-Guerrero etal., 2008; Vanholme etal., 2010; Li etal., 2011; Delgado-Cerezo et al., 2012; Thomas et al., 2013; Kim and Ralph, 2014).

Lignified cell walls represent the major proportion of the terrestrial plant biomass and an increasing demand for natural as well as "designer" plant material is observed (Boudet et al., 2003; Pu et al., 
2011). For an optimized production and utilization knowledge on the natural and modified material is of extreme importance. Due to the complex nature of plant cell walls knowledge on chemical composition as well as the structural arrangement at the different hierarchical levels (tissue, cell-micro and nano-level) is of importance as all together influence the properties. To reveal chemical information fast within the native cell wall different spectroscopy approaches have been developed (e.g., McCann et al., 1992; Oliveira et al., 2009; Robinson and Mansfield, 2009; Krongtaew et al., 2010; Lyubenova et al., 2012; Abidi et al., 2014). In combination with microscopy especially Confocal Raman imaging evolved as an important tool as molecular vibrations are monitored in context with the cell wall structure and thus the organization of components within the native wall of single cells is revealed (Agarwal, 2006; Gierlinger and Schwanninger, 2007; Gierlinger, 2011; Sun et al., 2011a; Gierlinger et al., 2013). Important information on cellulose microfibril orientation (Gierlinger et al., 2010b) and on the matrix polymers lignin and pectin can be revealed at once, so that a comprehensive picture of cell wall design is gained (Gierlinger and Schwanninger, 2006; Hanninen et al., 2011; Richter et al., 2011; Gierlinger et al., 2012; Perera et al., 2012).

Plant cell wall spectra are known to comprise broad and overlapping bands due to the intimate mixture of the different polymers and components and if the imaging approach is applied thousands of them are acquired (Gierlinger et al., 2012). Therefore data analysis of single spectra and single wavenumbers or bands has limitations and multivariate data analysis approaches high potential in elucidating changes in molecular structure (Shinzawa et al., 2009; Perera et al., 2011). In this paper vertex component analysis (VCA) is introduced as a promising approach for analyzing Raman maps of wooden cell walls. So far VCA has been successfully applied in the analysis of biomedical Raman images (Hedegaard et al., 2011; Krafft et al., 2011, 2012; Bergner et al., 2012; Ashtikar et al., 2013; Lattermann et al., 2013; Mazur etal., 2013), but not on plant cell walls. VCA belongs to the group of multivariate curve resolution methods and projects the data to the identified orthogonal subspace in an interactive way and finds the endmember by repeated iteration (Nascimento and Dias, 2005; Zhang and Tauler, 2013). The endmember spectra have been proposed to refer to the pure constituent spectra present in the image pixel (Zhang and Tauler, 2013). With this paper the feasibility of VCA to get new insights into the molecular structure of plant cell walls will be tested on Raman maps of softwood (spruce) and hardwood (beech). As the pure polymer and component might not be present at any single pixel of the Raman map not only pure components and endmember spectra are expected. The aim is therefore to differentiate first of all cell wall regions different in molecular structure and then get new insights into composition of these defined areas based on the analysis of the endmember spectra.

\section{MATERIALS AND METHODS SAMPLE PREPARATION}

From fresh spruce (Picea abies Karst) and beech (Fagus sylvatica) $8 \mu \mathrm{m}$ thick cross sections were cut using a rotary microtome
(LEICA RM2255, Germany). Placed on a glass slide a drop of $\mathrm{D}_{2} \mathrm{O}$ and a coverslip is added and sealed with nailpolish to avoid evaporation of $\mathrm{D}_{2} \mathrm{O}$ during the measurement.

\section{RAMAN IMAGING}

The Raman imaging measurements were performed with an InVia Renishaw Confocal Raman spectroscope (Renishaw, UK) using a $532 \mathrm{~nm}$ laser, an oil immersion objective (Nikon, 100x, $\mathrm{NA}=1.4$ ) and $1800 \mathrm{l} / \mathrm{mm}$ grating. For mapping a step size of $0.2 \mu \mathrm{m}$ (spruce) and $0,3 \mu \mathrm{m}$ (beech) and an integration time of $0.4 \mathrm{~s}$ was chosen in the StreamlineHR mode. After data acquisition a cosmic ray removal filter was applied using the Wire 3.7 software (Renishaw UK) and afterward data exported to Cytospec (v. 2.00.01) for univariate and multivariate data analysis data. Univariate data analysis was performed by calculating band areas and band height ratios of different wavenumber regions.

Different multivariate methods (principal component analysis, cluster analysis, vertex component analysis) were tested with and without baseline correction. The best results have been achieved with VCA, an unsupervised method to rapidly unmix hyperspectral data. Given a set of mixed spectral (multispectral or hyperspectral) vectors, the algorithm aims at estimating the number of reference substances, also called endmembers, their spectral signatures, and their abundance fractions. Unsupervised endmember extraction by VCA exploits the following facts: the endmembers are the vertices of a simplex and the affine transformation of a simplex is also a simplex. Furthermore, VCA assumes the presence of pure pixels in the data. The algorithm iteratively projects data onto a direction orthogonal to the subspace spanned by the endmembers already determined. The new endmember signature corresponds to the extreme of the projection (Nascimento and Dias, 2005). Applied on plant cell walls the extreme of the projection gives the purest found spectra (components) of the map and at the same time the distribution of the different endmembers (components) within the map is plotted in the images. VCA was tested with and without baseline correction and using different wavenumber regions. To choose the right number of endmembers values from 2 to 8 have been tested and evaluated based on the resulting endmember spectra and abundance map. With the given knowledge on plant cell wall composition and spectral signatures the final number of endmembers was chosen to represent areas and spectra, which represent distinct areas and differences.

The extracted endmember spectra were exported into OPUS 7.0 (Bruker, Germany) and for detailed analysis baseline corrected (rubberband) and min-max normalized on the aromatic stretching vibration around $1600 \mathrm{~cm}^{-1}$.

\section{RESULTS \\ SPRUCE EARLYWOOD AND LATEWOOD: UNIVARIATE IMAGING AND VERTEX COMPONENT ANALYSIS}

Raman mapping gives a fluorescence image by plotting the intensity change of the background (Figure 1A), which in wooden cell walls in many cases looks similar like integration of the main lignin bands between 1711 and $1533 \mathrm{~cm}^{-1}$ (Figure 1B). Cell wall corner (CC) and compound middle lamella (CML) show higher intensity (red color) due to higher amount of lignin, which is 


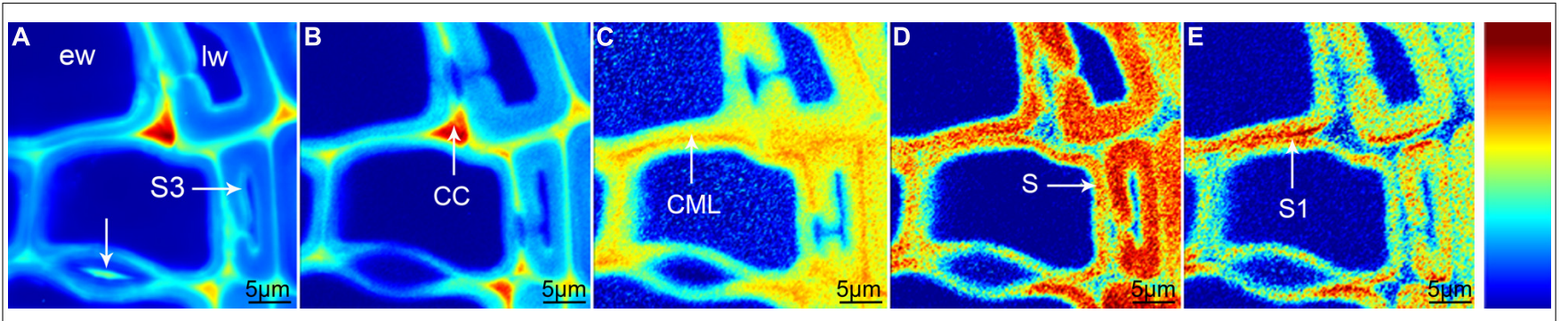

FIGURE 1 | Raman images of spruce wood cross sections $(38 \mu \mathrm{m} \times 38 \mu \mathrm{m})$ based on univariate analysis: fluorescence visualized by plotting the intensity from 500 to $600 \mathrm{~cm}^{-1} \quad$ (A), lignification by integration of the bands from 1711 to $1533 \mathrm{~cm}^{-1}$ (B), change in lignin composition by band height ratio of $1598 / 1657 \mathrm{~cm}^{-1} \quad$ (C), cellulose content by band integration from 401 to $331 \mathrm{~cm}^{-1}$ (D), change in orientation of cellulose microfibrils by integration from 1106 to $1083 \mathrm{~cm}^{-1}$ (E). the main cause of fluorescence. The main differences between the two pictures are that the pit membrane and the layer toward the lumen (S3) are emphasized in the fluorescence image (Figure 1A, arrows), but not in the lignin image (Figure 1B). An attempt to image not only changes in lignin amount, but also composition can be made by looking at the ratio of the intensity of the aromatic stretching vibration at $1599 \mathrm{~cm}^{-1}$ and the $1656 \mathrm{~cm}^{-1}$ band, assigned to $\mathrm{C}=\mathrm{C}$ of coniferyl alcohol and $\mathrm{C}=\mathrm{O}$ of coniferaldehydes (Agarwal etal., 2011; Figure 1C). By this the $\mathrm{CC}$ is no longer the region with highest intensity, but differs clearly together with CML from the secondary cell wall with a gradient toward the lumen (Figure 1C). Integration of the cellulose band at $380 \mathrm{~cm}^{-1}$ gives a clear picture of the secondary cell wall (Figure 1D) and due to changes in microfibril angle the S1 can be visualized by integrating the orientation sensitive band at $1095 \mathrm{~cm}^{-1}$ (Gierlinger and Schwanninger, 2006; Figure 1E). To really get a clear picture on chemistry and structure of the different visualized cell wall layers, underlying spectra have to be extracted for a detailed analysis (Gierlinger and Schwanninger, 2006; Richter et al., 2011). This can be time consuming and in many cases dependent on the personal view and therefore different multivariate approaches for image generation and spectra extraction have been explored.

The most promising multivariate data analysis method on the investigated plant cell wall maps was the VCA. Choosing four endmembers (EM) on the before shown Raman map gives a clear separation in three different cell components [CML and CC, lumenside layer (S3) and pit membrane, secondary cell wall (S)] and the lumen (Figure 2A). Abundance maps for every EM show in detail the distribution of the different components (Figures 2B-E) with black color for high abundance and white color for no contribution. The corresponding four endmember spectra give information about composition and structure of the identified component and/or anatomical region (Figures 2F,G). The first EM spectrum (blue) shows a high fluorescence background and the main lignin bands at 1599, $1656 \mathrm{~cm}^{-1}$ and a couple of medium bands between 1500 to $900 \mathrm{~cm}^{-1}$ (Figure 2F). Intensity is highest and restricted to the cell corner and the middle lamella (Figure 2B). The second EM spectrum (red) represents the lumen (Figure 2C) and has the highest band at $1204 \mathrm{~cm}^{-1}$ from $\mathrm{D}_{2} \mathrm{O}$ and some smaller bands in the lignin region, which might correspond to residual very weak lignin contribution from the cell corner and middle lamella region. The third EM (green) reveals a different lignin spectrum, again with high background and small broad bands with the most intense at $1603 \mathrm{~cm}^{-1}$ (Figure 2F). This characteristic EM spectrum refers to the pit membranes and inner secondary cell wall (S3) layer (Figure 2D). The fourth EM spectrum (black) corresponds to the main secondary cell wall S2 (Figure 2E) and shows marker bands of lignin (1656 and $\left.1599 \mathrm{~cm}^{-1}\right)$, cellulose $\left(1123,1094,381 \mathrm{~cm}^{-1}\right)$, and hemicellulose $\left(1722 \mathrm{~cm}^{-1}\right)$. Comparison of baseline-corrected and on the aromatic stretching band around $1600 \mathrm{~cm}^{-1}$ normalized spectra shows the detailed changes due to changes in lignin composition and cellulose orientation (Figure 2G). The cellulose orientation sensitive doublet at $1123 / 1094 \mathrm{~cm}^{-1}$ shows a clear change between the S3 and pit (green, EM3) compared to the secondary cell wall (black, EM4; Figure 2G). The $1094 \mathrm{~cm}^{-1}$ band is much higher than the $1123 \mathrm{~cm}^{-1}$ band in the $S 3$ and pit membrane (green, EM3). This means that the cellulose microfibrils are oriented with a high angle with respect to the fiber axis (Gierlinger et al., 2010b) in this region. The lignin composition changes between all three cell wall positions as can be seen by the different heights of the 1656 and $1632 \mathrm{~cm}^{-1}$ band as well as the change in peak position of the aromatic ring stretching vibration from 1599 in the thick S-layer to $1603 \mathrm{~cm}^{-1}$ in the S3 layer and pit membrane (Figure 2G). So from these VCA result we can conclude that the interface toward the lumen (S3) have similar lignin structure like the pit membrane and differ clearly from the S2 layer and CML. The $1655 \mathrm{~cm}^{-1}$ band, is reduced, whereas the band at $1632 \mathrm{~cm}^{-1}$, is enhanced. In the CML the two bands are in between the S3 and S2 layer. The $1452 \mathrm{~cm}^{-1}$ band, assigned to $\mathrm{CH}_{3}$ bending in $\mathrm{OCH}_{3}$ (Agarwal et al., 2011) is clearly increased in the $\mathrm{S}$ layer and lowest in the CML, but might be influenced by the increase of the underlying cellulose band at $1472 \mathrm{~cm}^{-1}$.

\section{BEECH FIBERS AND VESSELS: VERTEX COMPONENT ANALYSIS}

Vertex component analysis analysis of beech cross sections give on first hand similar Raman pictures separating the same three cell wall regions and the lumen (Figures 3A-E). Cell corners and CML are separated (Figures $\mathbf{3 A}, \mathbf{B}$ ) by the first EM and the spectrum shows again high fluorescence and mainly lignin bands (blue, Figure 3F). Due to the different lignin composition of hardwoods changes in the beech spectra are observed, e.g., the more 


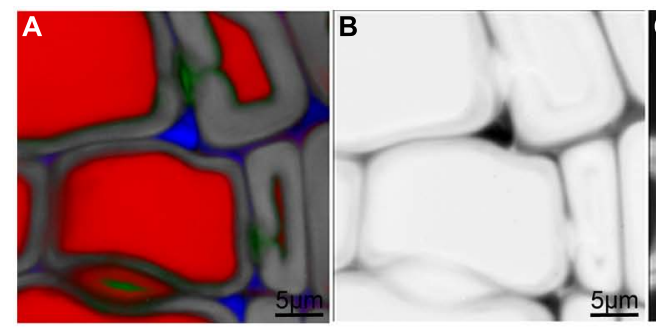

$\mathbf{F}$

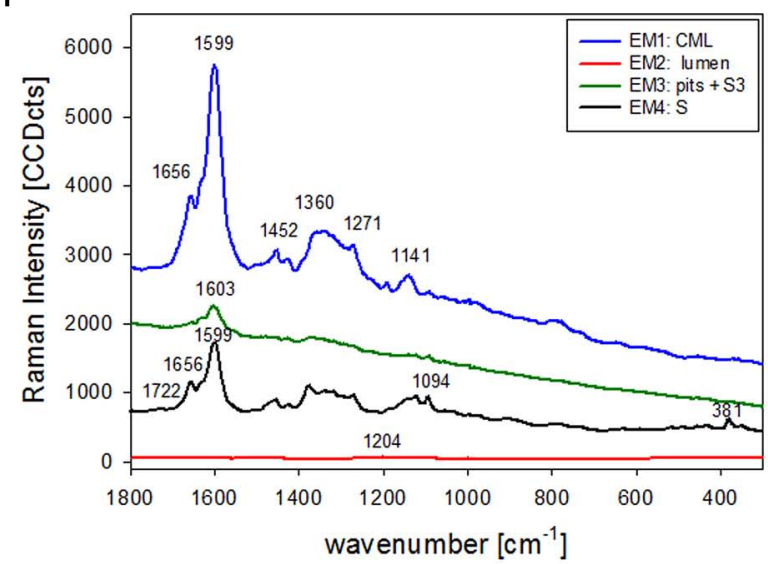

FIGURE 2 | Raman images of spruce wood cross sections $(38 \mu \mathrm{m} \times 38 \mu \mathrm{m})$ based on VCA analysis with four endmembers using the wavenumber region from 1800 to $300 \mathrm{~cm}^{-1}$ : colored composite image visualizing all four endmembers (EM; $A$ ) and intensity changes of EM 1 corresponding to cell corners (B), EM 2 reflecting the lumen (C), EM

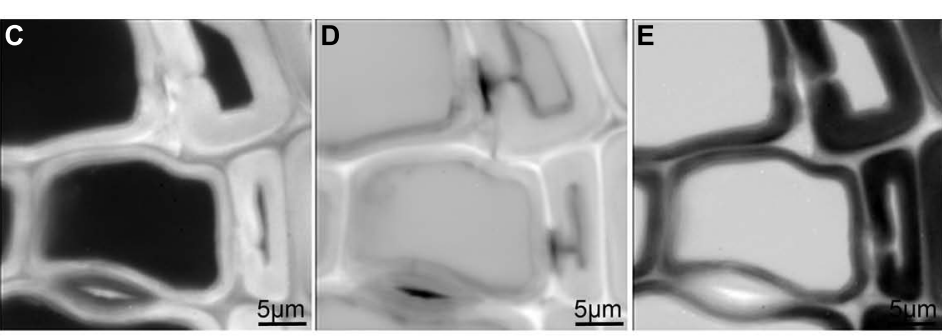

$\mathbf{G}$

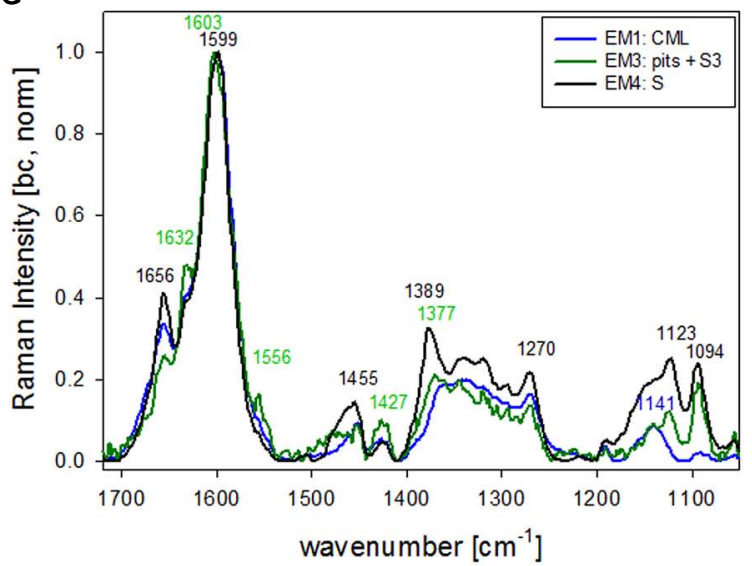

3 with high intensity in pit membrane and layer toward the lumen (S3; D), and EM 4 representing the secondary cell wall (E). The corresponding endmember spectra are shown with original background and intensity (F) and after baseline correction and normalization on the aromatic stretching vibration at $1599 \mathrm{~cm}^{-1}$ (G) pronounced band at $1332 \mathrm{~cm}^{-1}$ (Figure 3F), assigned to aliphatic O-H bending (Agarwal et al., 2011). Again the second EM represents mainly the lumen with $\mathrm{D}_{2} \mathrm{O}$ (Figure 3C) and the third EM reflects the pit membranes and linked connections to the inner layer (S3; Figure 3D). Compared to EM three in spruce (Figure 2D) more abundance within the thick secondary cell wall (medium gray) is observed and partly strong signal in the vessels (left upper and right lower corner, Figure 3D). The corresponding EM spectrum shows like in spruce quite high fluorescence (Figure 3F) and strong contributions from lignin (Figures 3F,G). The last EM describes the main secondary cell wall, having beside the lignin bands also clear signals from cellulose at 1378, 1121, $1093,378 \mathrm{~cm}^{-1}$ and hemicellulose at $1730 \mathrm{~cm}^{-1}$ (Figures 3F,G). A zoom into the strong lignin region shows that in beech EM1, the CC and CML showed the highest shoulder around $1632 \mathrm{~cm}^{-1}$. Like in spruce the band at $1658 \mathrm{~cm}^{-1}$ is increased in the secondary cell wall (Figure 3G).

The chosen number of EMs in the VCA has an influence on the results as well as the selected area, wavenumber region or spectral pretreatment and has to be adjusted according to the research question. In the given examples four EMs have been shown to separate cell wall structures most different in lignin content and/or composition, when the analysis is based on untreated spectra from 300 to $1800 \mathrm{~cm}^{-1}$ (Figures 2 and 3 ). To reveal additional differences and heterogeneity of the cell wall of vessels and fibers a smaller region excluding the highly lignified cell corners and pit membranes was chosen (inset in Figure 3A) and analyzed with five EMs (Figures 4A-G). By this not only the lumen oriented S3 of the secondary cell wall was separated, but also the S1 within the fiber and the vessel wall (Figure 4A). All five EM spectra showed a similar intensity range and background as the highly lignified CC and pit region has been excluded (Figure 4F). The CML is clearly separated by the second EM (Figure 4B, first EM corresponds to the lumen and is not shown), which shows the highest lignification, but also contribution from cellulose bands (red, Figure 4F). The $1093 \mathrm{~cm}^{-1}$ band is much higher than the $1121 \mathrm{~cm}^{-1}$ band pointing to alignment of the cellulose fibrils with a high angle in respect to the fiber axis (Gierlinger et al., 2010a). The third EM describes the main secondary cell wall of the fiber and partly the vessel (Figure 4C) with the lowest lignin content and cellulose microfibrils aligned parallel to the fiber axis, as expressed by the ratio of the 1121 and $1093 \mathrm{~cm}^{-1}$ band (green, Figures 4F,G). The fourth EM is again the lumen-sided S3 layer (Figure 4D) with high fluorescence (black, Figure 4F) and more noisy slightly changed lignin bands (Figure 4G). The fifth EM now clearly separates the S1 layer of the fiber and vessel, but also the lumen part of the vessel wall (S3, Figure 4E). These regions are described by slightly higher lignin content than the main secondary cell wall and a high microfibril angle (with respect to the fiber axis, Figures 4F,G). So it can be concluded that most of the vessel wall is ascribed to higher lignin content and higher microfibril angle with respect to the fiber axis (cyan EM5 and black EM4, 

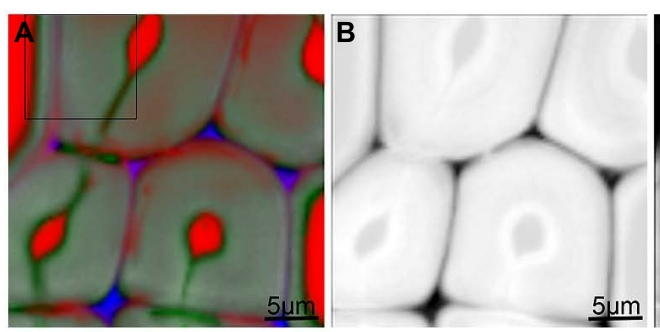

$\mathbf{F}$

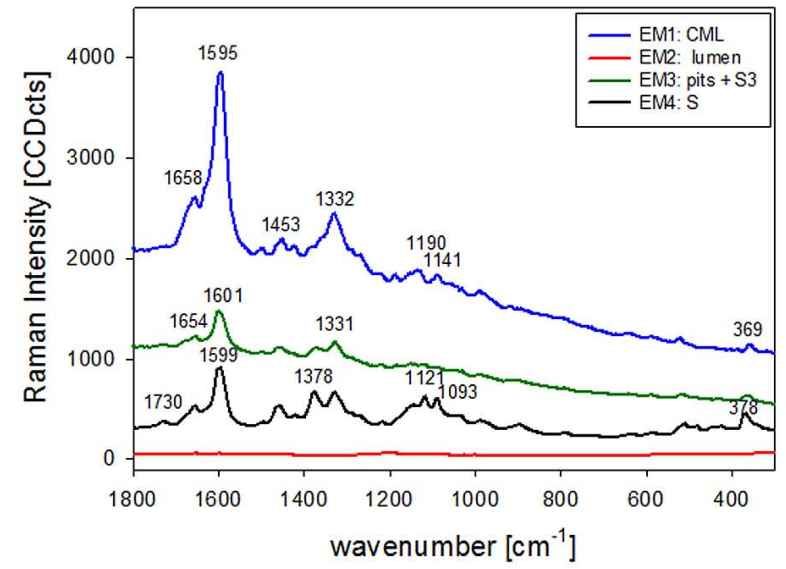

FIGURE 3 | Raman images of beech wood cross sections $(30 \mu \mathrm{m} \times 30 \mu \mathrm{m})$ based on VCA analysis with four endmembers using the wavenumber region from 1800 to $300 \mathrm{~cm}^{-1}$ : colored composite image visualizing all four endmembers (EM; $A$ ) and intensity changes of EM 1 corresponding to cell corners (B), EM 2 reflecting the lumen (C), EM
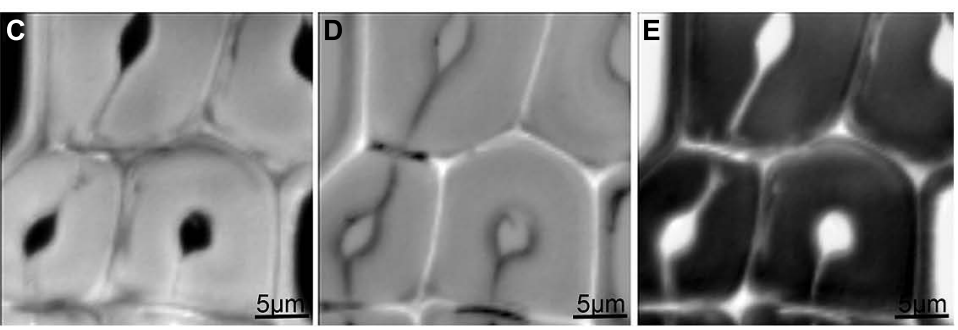

$\mathbf{G}$

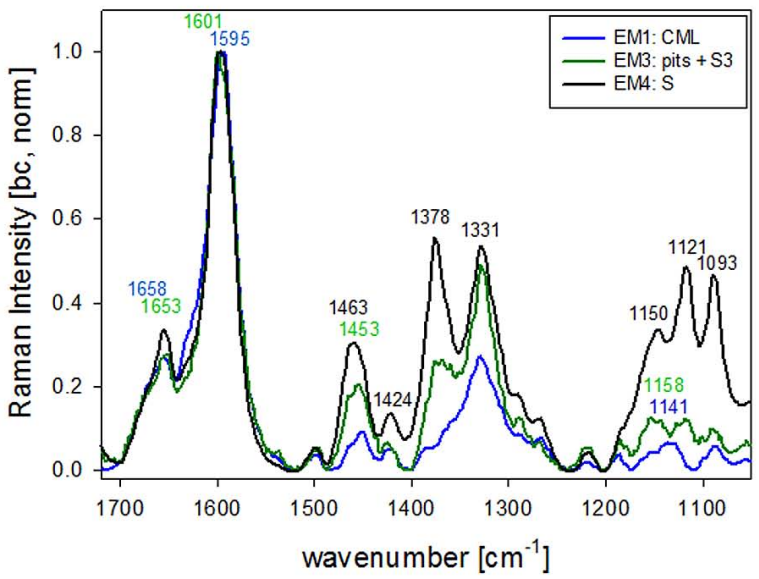

3 with high intensity in pit membrane and layer toward the lumen (S3; $D)$, and EM 4 representing the secondary cell wall (E). The corresponding EM spectra are shown with original background and intensity (F) and after baseline correction and normalization on the aromatic stretching vibration at $1599 \mathrm{~cm}^{-1}$ (G).
Figures 4D,E) than the secondary cell wall of the fiber (red EM2, Figure 4C).

After clear distinction of the cell wall layers (CC-CML-S1-S2S3) based on changes in molecular structure, the question arised if the S2 fiber cell wall is really of uniform molecular composition or if VCA could visualize also subtle differences by analyzing solely the S2 layer. Therefore in a next step a zoom into the secondary cell wall (inset in Figure 4A) was analyzed using two EMs (Figures 5A-D). By this a lamellar structure was revealed (Figures 5A-C) with slightly changing lignin amount and composition (Figure 5D). Although the spectral (molecular) changes are small these lamellar structure have been revealed at different positions (zooms) and independent Raman maps.

\section{DISCUSSION}

\section{UNIVARIATE VERSUS MULTIVARIATE DATA ANALYSIS METHODS}

The Raman imaging approach based on univariate data analysis (Figure 1) gives quite important insights into plant cell wall design, but has some drawbacks. To relate intensity changes of a certain band directly to changes in the amount of a specific single cell wall component or functional group is only possible if intensity changes due to different focal points (changes in sample height) can be excluded and the band of interest has no overlap with other bands attributed to different components. By preparing very plane sample surfaces or by plotting ratios of selected bands the intensity changes due to different sample heights (focus) can be eliminated. Nevertheless the following problems of univariate analysis remain: (1) plant cell wall spectra are characterized by broad overlapping bands and only a few marker bands which are not influenced by neighboring and/or underlying bands and/or shoulders of other components or functional groups are present (2) not only the amount, but also changes in polymer composition and/or form (e.g., crystallinity) and/or orientation are influencing Raman band shape and intensity. Therefore interpretation of images based on univariate data analysis should always include detailed analysis and/or control of the underlying spectra. Yet this is often neglected, because average or characteristic spectra of selected regions are not automatically calculated by the software. Furthermore calculating average spectra can be time consuming and region selection or intensity threshold definition depends on the personal view and the beforehand calculated image.

Multivariate methods overcome the problem of overlapping bands as the whole spectra or wider spectral regions are analyzed. Additionally to the derived Raman images the corresponding average spectra (cluster analysis), loadings (Principal component analysis) or endmembers (VCA) are available for data interpretation. The three mentioned multivariate approaches have been tested on different plant cell wall Raman maps and as VCA gave the best results only these have been shown here. Best results are 

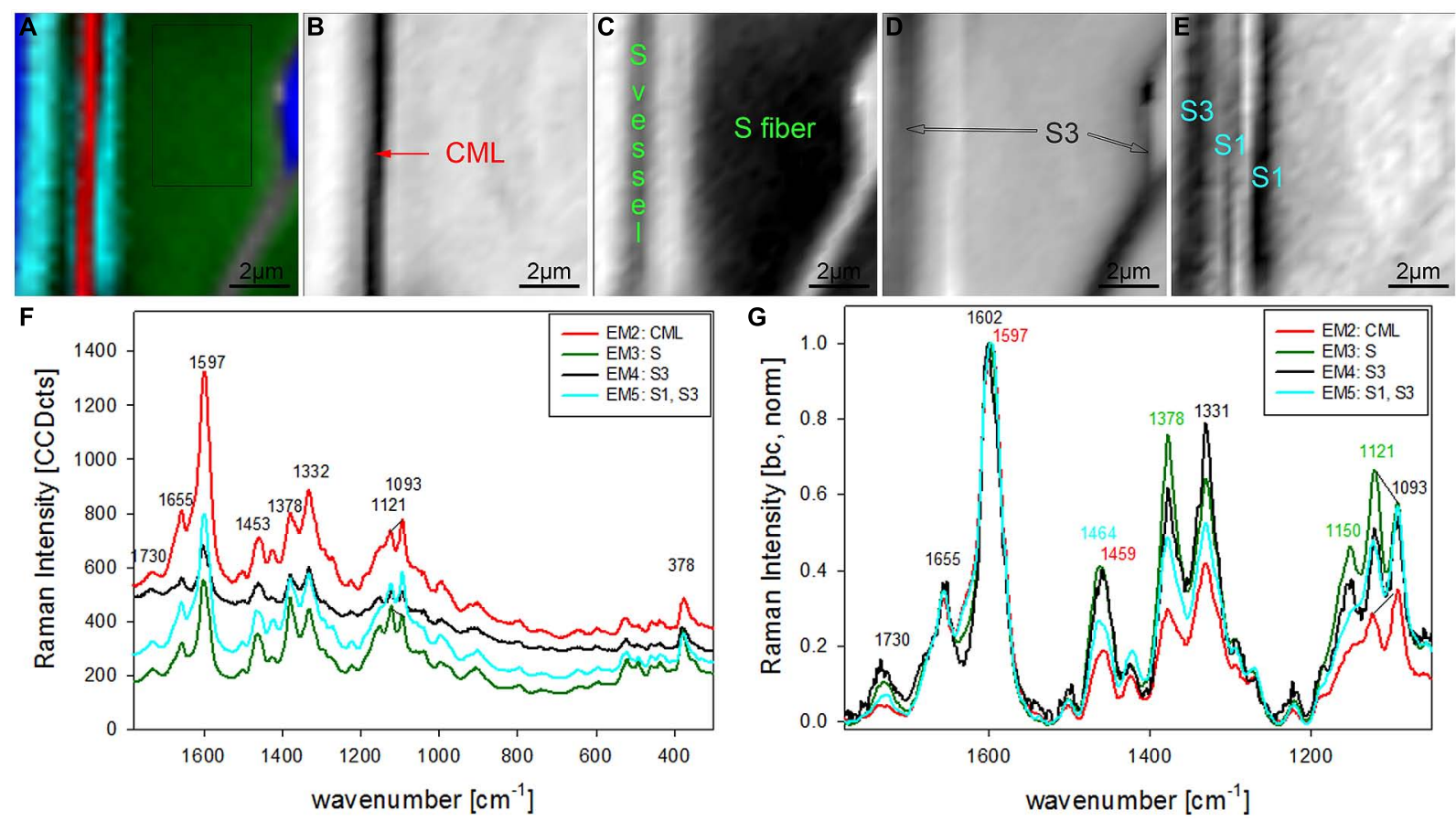

FIGURE 4 | Raman images of zoom into beech wood fiber and vessel wall $(10 \mu \mathrm{m} \times 10 \mu \mathrm{m})$ based on VCA analysis with five endmembers using the wavenumber region from 1800 to $300 \mathrm{~cm}^{-1}$ : colored composite image visualizing all five endmembers (EM; $A$ ) and intensity changes of EM 2 corresponding to cell corners (B), EM 3 reflecting the secondary cell wall (C), EM 4 with high intensity in the layers toward the lumen (S3; D), and EM 5 representing the S1 and S3 layer (E). The corresponding EM spectra are shown with original background and intensity (F) and after baseline correction and normalization on the aromatic stretching vibration at $1599 \mathrm{~cm}^{-1}$ (G) considered as coming up with the most reasonable distinction of regions and/or layers and spectra or loadings or endmembers, which represent most pure component or layer spectra. Another advantage has been the fact that good results have been achieved even without baseline correction, which was not the case for most of the other approaches.

In the univariate analysis $\mathrm{CC}$ and CML could be visualized due to the changes in the lignin band (Figures 1B,C) and the S1 and the whole $S$ wall by integrating cellulose bands (Figures 1D,E). The S3 and pit-membrane were only visible in the fluorescence image (plotting intensity change in a region without a band, Figure 1A). The VCA analysis revealed for the first time that pit membranes and the inner S3 layer have a similar molecular structure, which differs clearly from all other regions (Figures 2D and 3D). Furthermore a lamellar structure within the secondary cell wall has been visualized by Raman VCA imaging (Figure 5). VCA clearly finds the most relevant and also subtle molecular changes within one image scan (4.2) and additionally opens up new opportunities for comparing different samples based on the EM spectra (4.3).

\section{CHANGES IN LIGNIN AMOUNT AND COMPOSITION IN DIFFERENT CELL WALL REGIONS}

Vertex component analysis images and EM spectra clearly demonstrated that not only the amount of lignin is changing between the different cell wall regions and layers, but also lignin composition. It is already known that the amount and chemical characteristics of lignin vary across the cell wall, with the presence of reaction wood and among cell types (Donaldson, 2001). It is difficult to perform reliable chemical analysis of lignin from separate layers in wood as many different cell types and tissues are present and fractionations tend to include mixtures and thus give uncertain results. Therefore a variety of microscopy techniques including microautoradiography, histochemistry, UV absorbance, interference microscopy, fluorescence and transmission electron microscopy have been applied. The higher amount of lignin in CML and CC compared to the secondary cell wall was verified using many different methods (Donaldson, 2001). By selective labeling of $p$-hydroxyphenyl-guaiacyl and syringylpropane moieties the growing process of protolignin macromolecule in specific morphological region was visualized by high resolution microautoradiography and the content of condensed lignin is reported to be higher in the cell corner and middle lamella than in secondary cell wall lignin (Terashima and Fukushima, 1988). The normalized EM spectra corresponding to the two different anatomical regions (Figures $\mathbf{2 G}$ and $\mathbf{3 G}$ ) confirm this result by a relative decrease of the band at $1656 \mathrm{~cm}^{-1}$ (spruce) and $1658 \mathrm{~cm}^{-1}$ (beech), which is assigned to $\mathrm{C}=\mathrm{C}$ of coniferyl alcohol and $\mathrm{C}=\mathrm{O}$ of coniferaldehydes (Agarwal et al., 2011) in the CML compared to the secondary cell wall. In spruce the EM corresponding mainly to the pits (and partly S3 layer; green line Figure 2G) shows an even higher decrease of the $1656 \mathrm{~cm}^{-1}$ band which might be explained by the fact that lignification starts in the middle lamella between pit borders (Kutscha and 


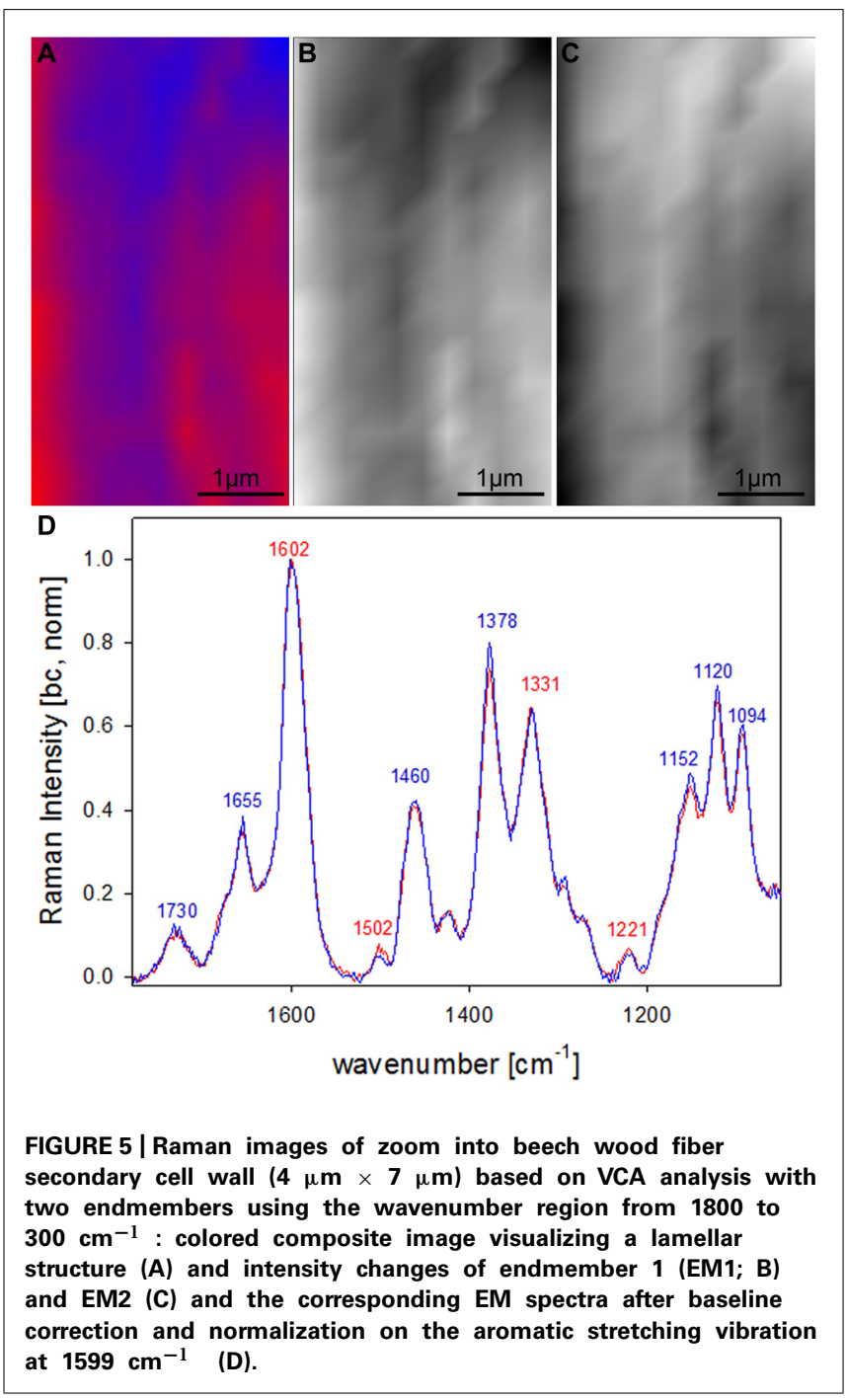

Schwarzmann, 1975) and thus probably representing the oldest developmental stage of lignification within the scanned area. As the maps are within the last two annual growth rings of fresh never dried-out sapwood the question arises if lignin polymerization is already completely finished or not. The method thus will have the potential to clarify the lignin polymerization process by a detailed study from cambium to the sapwood/heartwood border.

Together with the described band decrease a band arises at $1632 \mathrm{~cm}^{-1}$ in the pit (S3) EM spectra (green line Figure 2G). An increase of a band at $1630 \mathrm{~cm}^{-1}$ was reported in anti-sense CAD clones of tobacco plants and attributed to incorporation of coniferaldehyde like moieties into the lignin structure (Stewart et al., 1997). Coniferaldehyde can be the direct precursor of coniferyl alcohol, but is also known to be formed in the course of dehydropolymerization of coniferyl alcohol (Boerjan et al., 2003; Higuchi, 2006). Possibly also stilbenes contribute in this region, as a marker band is reported at $1635 \mathrm{~cm}^{-1}$ (Agarwal and Atalla, 2000). The broadening and shift to higher wavenumber of the aromatic stretching vibration in the pit and S3 membran may also suggest the formation of $o$ - and $p$-quinone type structures, like reported in the phodegradation study of wood (Pandey and Vuorinen, 2008). Also the shoulder/band at $1556 \mathrm{~cm}^{-1}$ could be attributed to o-quinone (Agarwal and Atalla, 2000). The high fluorescence in relation to the low band intensity (Figures 2F and $3 \mathbf{F}$, green line) probably comes from chromophores and a more conjugated system over the aromatic rings (Lahdetie et al., 2013). So we can conclude that more oxidized lignin moieties are found in the surface layers represented by pit membrane and S3 layer. The degree of oxidization is suggested to have an effect on function and treatment of woody structures and is thus of great research interest. So far the S3 layer has often been reported to be more highly lignified than the adjacent S2 layer (Donaldson, 1987), but depending on the technique results on increased content might also be influenced by changes in lignin composition.

In spruce the earlywood has higher contribution in EM3 (Figure 2D) than the latewood and in beech the vessel higher than the fiber (Figure 3D). As the changed lignin composition in pits and S3 is more pronounced in the tissue (earlywood) and elements (vessels) specialized on water conduction in the tree, a role or support for this functionality is suggested. The band characteristic for syringyl units at $1331 \mathrm{~cm}^{-1}$ clearly increased in the secondary cell wall EM spectra (Figure 3G, green and black line) compared to the CML (Figure 3G, blue line). This is in accordance with results that syringyl lignin are deposited especially during the late stages of secondary cell wall formation in hardwood fibers (Ruel et al., 1999).

\section{Lamellar structure in beech}

By restricting the VCA analysis on a small region within the S2 layer of the thick walled fibers a lamellar structure was revealed (Figures 5A-C). The endmember spectra showed that these differentiation is based on subtle changes of the lignin content and composition (Figure 5D). Although these spectra are far away from pure component spectra and changes are small, a lamellar structure was revealed, which has not been seen by univariate approaches. Similar segmented circumferential nanostructure in the $100 \mathrm{~nm}$ range have been seen recently by applying for the first time near-field scanning optical microscopy (SNOM) on secondary plant cell walls. Based on comparative analysis of model substances the elucidated nanoscale structure was suggested to reflect variations in lignification within the secondary cell wall (Keplinger et al., 2014). Within this study VCA Raman imaging proved the assumption of lamellar changes of lignin composition and content, which probably is due to non-uniform lignification during growth.

\section{COMPARING DIFFERENT SAMPLES BASED ON ENDMEMBER SPECTRA}

Based on the EM spectra it is now possible to compare samples (in our case beech and spruce) based on the found extreme projections (EM spectra). If comparison is the aim of the study care should be taken to use parameters (wavelength region, selected sample area, number of endmembers) that reveal the same distinguished cell wall areas (e.g., in the shown example: CML, S, pits, and S3). This enables a comparison based on the selected regions, which will bring new insights into the effect of different modifications (e.g., 

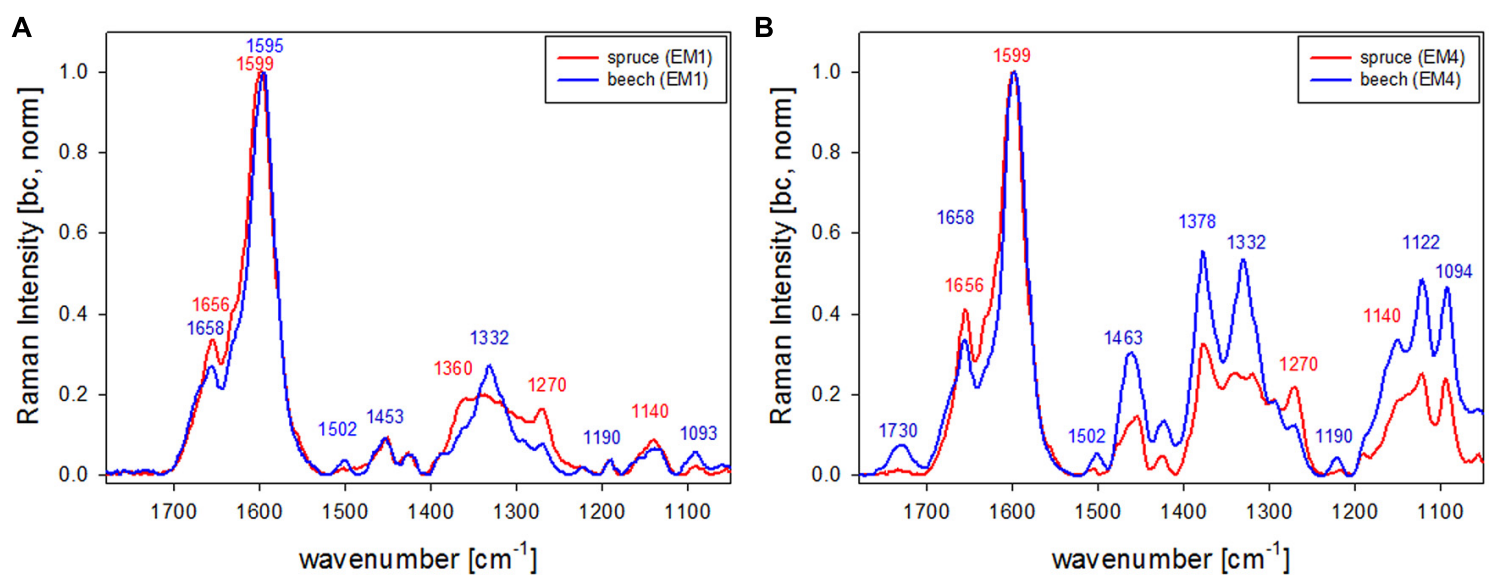

FIGURE 6 | Comparison of Raman spectra of spruce and beech after baseline correction and normalization on the aromatic stretching vibration at $1599 \mathrm{~cm}^{-1}$ based the analysis shown in Figures 2 and 3 representing CC and CML (EM1, A) and the secondary cell wall (EM4, B; red line: spruce, blue line: beech).

genetic or chemical). Not only the general change can be probed, but information whether the changes are uniform or selected parts of the cell wall are more or less affected.

The first EM spectra of spruce and beech have been identified as almost pure lignin spectra as no contributions from carbohydrates are seen (Figures 2F,G and 3F,G). So VCA enabled to extract spectra from native softwood and hardwood lignin by looking at the most extreme projections in the dataset, which are located as expected in the CC (Figures 2B and 3B). Comparing the two shows clearly that intensity and also the background was higher in spruce (Figures $\mathbf{2 F}$ and $\mathbf{3 F}$ ), which is explained by the different lignin amount and structure. When comparing the normalized lignin spectra clear differences are seen in band intensities and positions (Figure 5A). The difference in intensity comes from higher lignin amount in spruce and different concentration of aromatic ring-conjugated structures. This is supported by a decrease of the $1630 \mathrm{~cm}^{-1}$ shoulder assigned to coniferylaldehyde/sinapaldehyde and the $1658 \mathrm{~cm}^{-1}$ band, where also coniferyl alcohol/sinapyl alcohol contribute. The higher cinnamaldehyd structure content in spruce is also supported by the higher band at $1140 \mathrm{~cm}^{-1}$. The aromatic ring stretching vibration changes position from $1595 \mathrm{~cm}^{-1}$ in beech to $1599 \mathrm{~cm}^{-1}$ in spruce in accordance with Raman spectra of milled-wood lignins of softwood and hardwood (Agarwal et al., 2011).

Besides typical higher bands in spruce are at $1360 \mathrm{~cm}^{-1}$ (CH-bending in $\mathrm{R} 3 \mathrm{C}-\mathrm{H}$ ), $1294 \mathrm{~cm}^{-1}$ (Aryl-O of aryl-OH and aryl-O-CH $3, \mathrm{C}-\mathrm{C}$ stretch of coniferyl alcohol) and $1270 \mathrm{~cm}^{-1}$ [Aryl- $\mathrm{O}$ of aryl-OH and aryl-O- $\mathrm{CH}_{3}$, guaiacyl/syringyl ring (with $\mathrm{C}=\mathrm{O}$ group) mode], while the $1332 \mathrm{~cm}^{-1}$ (aliphatic $\mathrm{O}-\mathrm{H}$ bending) band is more characteristic and sharp in beech. The $1332 \mathrm{~cm}^{-1}$ band is therefore often used as a marker band for syringyl units, whereas the 1270 band is taken for guaicyl (Sun et al., 2011b). The overlapping nature in this band region is seen in the pure lignin spectra, especially in softwoods (Figure 6A). Looking at the spectra of secondary cell wall (Figure 6B, EM4) it becomes clear that not only the lignin modes overlap, but additionally the cellulose bands at 1378 and $1342 \mathrm{~cm}^{-1}$ contribute in this region and make a straightforward accurate determination of $S / G$ ratio using these two bands and spectral fitting quite challenging, especially when cellulose content changes too. Nevertheless by including samples with quite different chemistry (Eucalyptus, maize, Sorghum, Arabidopsis, switchgrass) and ratios (0.04-1.68) a calibration curve was established by Sun et al. (2011b).

What is also clearly seen in the comparison of the secondary cell wall of spruce and beech (Figure 6B) is the change in hemicellulose composition. While in spruce almost no signal is found at $1730 \mathrm{~cm}^{-1}$, a clear band evolved in the beech, which is attributed to ester carbonyl groups from xylans (Lewis et al., 1994).

Investigating the Raman spectrum over the whole spectral range with VCA gives clearly the advantage that all polymers are studied at once and in terms of all aspects: orientation, content, and composition. VCA imaging has proven to be able to visualize also subtle differences in molecular structure. The extracted endmember spectra included only one pure component spectrum of lignin from the cell corner regions. All others represent mixtures, which are characteristic for the different resolved spatial areas and thus give detailed information on the changes in the molecular structure between these regions and different species.

\section{ACKNOWLEDGMENTS}

This work was supported by the European Commission's Seventh Framework Program (MultiBioPro 2700089) and the START Project [Y-728-B16] from the Austrian Science Fund (FWF). The Wood Materials Science group at ETH and Empa is supported by BAFU (Bundesamt für Umwelt) and Lignum, Switzerland.

\section{REFERENCES}

Abidi, N., Cabrales, L., and Haigler, C. H. (2014). Changes in the cell wall and cellulose content of developing cotton fibers investigated by FTIR spectroscopy. Carbohydr. Polym. 100, 9-16. doi: 10.1016/j.carbpol.2013.01.074 
Agarwal, U. (2006). Raman imaging to investigate ultrastructure and composition of plant cell walls: distribution of lignin and cellulose in black spruce wood (Picea mariana). Planta 224, 1141-1153. doi: 10.1007/s00425-006-0295-Z

Agarwal, U. P., and Atalla, R. H. (2000). "Using Raman spectroscopy to identify chromophores in lignin-lignocellulosics," in Lignin: Historical, Biological, and Materials Perspectives, ACS Symposium Series, eds W. G. Glasser, R. A. Northey, and T. P. Schultz (Washington, DC: American Chemical Society), 250-264.

Agarwal, U. P., McSweeny, J. D., and Ralph, S. A. (2011). FT-Raman investigation of milled-wood lignins: softwood, hardwood, and chemically modified black spruce lignins. J. Wood Chem. Technol. 31, 324-344. doi: 10.1080/02773813.2011.562338

Artz, R. R. E., Chapmana, S. J., Jean Robertsona, A. H., Pottsb, J. M., LaggounDéfargec, F., Gogoc, S., etal. (2008). FTIR spectroscopy can be used as a screening tool for organic matter quality in regenerating cutover peatlands. Soil Biol. Biochem. 40, 515-527. doi: 10.1016/j.soilbio.2007.09.019

Ashtikar, M., Matthäus, C., Schmitt, M., Krafft, C., Fahr, A., and Popp, J. (2013). Non-invasive depth profile imaging of the stratum corneum using confocal Raman microscopy: first insights into the method. Eur. J. Pharm. Sci. 50, 601-608. doi: 10.1016/j.ejps.2013.05.030

Bergner, N., Romeike, B. F., Reichart, R., Kalff, R., Krafft, C., and Popp, J. (2012). Identification of primary tumors of brain metastases by Raman imaging and support vector machines. Chemometr. Intell. Lab. Syst. 117, 224-232. doi: 10.1016/j.chemolab.2012.02.008

Bhatt, N., Gupta, P. K., and Naithani, S. (2008). Preparation of cellulose sulfate from $\alpha$-cellulose isolated from Lantana camara by the direct esterification method. J. Appl. Polym. Sci. 108, 2895-2901. doi: 10.1002/App.27773

Boerjan, W., Ralph, J., and Baucher, M. (2003). Lignin biosynthesis. Annu. Rev. Plant Biol. 54, 519-543. doi: 10.1146/annurev.arplant.54.031902.134938

Boudet, A. M., Kajita, S., Grima-Pettenati, J., and Goffner, D. (2003). Lignins and lignocellulosics: a better control of synthesis for new and improved uses. Trends Plant Sci. 8, 576-581. doi: 10.1016/j.tplants.2003.10.001

Cosgrove, D. J. (2005). Growth of the plant cell wall. Nat. Rev. Mol. Cell Biol. 6, 850-861. doi: 10.1038/nrm1746

Delgado-Cerezo, M., Sánchez-Rodríguez, C., Escudero, V., Miedes, E., Fernández, P. V., Jordá, L., et al. (2012). Arabidopsis heterotrimeric G-protein regulates cell wall defense and resistance to necrotrophic fungi. Mol. Plant 5, 98-114. doi: $10.1093 / \mathrm{Mp} / \mathrm{Ssr} 082$

Donaldson, L. A. (1987). S3-Lignin concentration in radiata pine tracheids. Wood Sci. Technol. 21, 227-234. doi: 10.1007/BF00351394

Donaldson, L. A. (2001). Lignification and lignin topochemistry - an ultrastructural view. Phytochemistry 57, 859-873. doi: 10.1016/S0031-9422(01)00049-8

Gierlinger, N. (2011). "Raman imaging of plant cell walls," in Confocal Raman Microscopy, Vol. 158, eds T. Dieing, O. Hollricher, and J. Toporski (BerlinHeidelberg: Springer), 225-236. doi: 10.1007/978-3-642-12522-5

Gierlinger, N., Keplinger, T., and Harrington, M. (2012). Imaging of plant cell walls by confocal Raman microscopy. Nat. Protoc. 7, 1694-1708. doi 10.1038/nprot.2012.092

Gierlinger, N., Keplinger, T., Harrington, M., and Schwanninger, M. (2013). "Raman imaging of lignocellulosic feedstock," in Cellulose - Biomass Conversion, eds T. van de Ven and J. Kadla (Rijeka: INTECH). doi: 10.5772/50878

Gierlinger, N., Luss, S., König, C., Konnerth, J., Eder, M., and Fratzl, P. (2010a). Cellulose microfibril orientation of Picea abies and its variability at the micronlevel determined by Raman imaging. J. Exp. Bot. 61, 587-595. doi: 10.1093/jxb/ erp325

Gierlinger, N., Matthäus, C., Schmitt, M., Krafft, C., Fahr, A., and Popp, J. (2010b). Cellulose microfibril orientation of Picea abies and its variability at the micron-level determined by Raman imaging. J. Exp. Bot. 61, 587-595. doi: $10.1093 /$ jxb/erp325

Gierlinger, N., and Schwanninger, M. (2006). Chemical imaging of poplar wood cell walls by confocal Raman microscopy. Plant Physiol. 140, 1246-1254. doi: 10.1104/pp.105.066993

Gierlinger, N., and Schwanninger, M. (2007). The potential of Raman microscopy and Raman imaging in plant research - review. Spectroscopy 21, 69-89. doi: $10.1155 / 2007 / 498206$

Gonzalez-Guerrero, M., Melville, L. H., Ferrol, N., Lott, J. N., Azcón-Aguilar, C., and Peterson, R. L. (2008). Ultrastructural localization of heavy metals in the extraradical mycelium and spores of the arbuscular mycorrhizal fungus Glomus intraradices. Can. J. Microbiol. 54, 103-110. doi: 10.1139/W07-119

Hanninen, T., Kontturi, E., and Vuorinen, T. (2011). Distribution of lignin and its coniferyl alcohol and coniferyl aldehyde groups in Picea abies and Pinus sylvestris as observed by Raman imaging. Phytochemistry 72, 1889-1895. doi: 10.1016/j.phytochem.2011.05.005

Hedegaard, M., Matthäus, C., Hassing, S., Krafft, C., Diem, M., and Popp, J. (2011). Spectral unmixing and clustering algorithms for assessment of single cells by Raman microscopic imaging. Theor. Chem. Acc. 130, 1249-1260. doi: 10.1007/s00214-011-0957-1

Higuchi, T. (2006). Look back over the studies of lignin biochemistry. J. Wood Sci. 52, 2-8. doi: 10.1007/s10086-005-0790-z

Keegstra, K. (2010). Plant cell walls. Plant Physiol. 154, 483-486. doi: 10.1104/pp.110.161240

Keplinger, T., Konnerth, J., Aguié-Béghin, V., Rüggeberg, M., Gierlinger, N., Burgert, I., et al. (2014). A zoom into the nanoscale texture of secondary cell walls. Plant Methods 10, 1. doi: 10.1186/1746-4811-10-1

Kim, H., and Ralph, J. (2014). A gel-state 2D-NMR method for plant cell wall profiling and analysis: a model study with the amorphous cellulose and xylan from ball-milled cotton linters. RSC Adv. 4, 7549-7560. doi: 10.1039/ C3ra46338a

Krafft, C., Bergner, N., Romeike, B., Reichart, R., Kalff, R., Geiger, K., et al. (2012). "Raman spectroscopic imaging as complementary tool for histopathologic assessment of brain tumors," in Proceedings of the SPIE 8207 Photonic Therapeutics and Diagnostics VIII, Parts 1 and 2, Vol. 8207, San Francisco, CA.

Krafft, C., Diderhoshan, M. A., Recknagel, P., Miljkovic, M., Bauer, M., and Popp J. (2011). Crisp and soft multivariate methods visualize individual cell nuclei in Raman images of liver tissue sections. Vib. Spectrosc. 55, 90-100. doi: 10.1016/j.vibspec.2010.09.003

Krongtaew, C., Messner, K., Ters, T., and Fackler, K. (2010). Characterization of key parameters for biotechnological lignocellulose conversion assessed by Ft-Nir spectroscopy. Part II: quantitative analysis by partial least squares regression. Bioresources 5, 2081-2096.

Kutscha, N. P., and Schwarzmann, J. M. (1975). Lignification sequence in normal wood of balsam fir (Abies balsamea). Holzforschung 29, 79-84. doi: 10.1515/hfsg.1975.29.3.79

Lahdetie, A., Nousiainen, P., Sipila, J., Tamminen, T., and Jaaskelainen, A. S. (2013). Laser-induced fluorescence (LIF) of lignin and lignin model compounds in Raman spectroscopy. Holzforschung 67, 531-538. doi: 10.1515/hf2012-0177

Lattermann, A., Matthäus, C., Bergner, N., Beleites, C., Romeike, B. F., Krafft, C., et al. (2013). Characterization of atherosclerotic plaque depositions by Raman and FTIR imaging. J. Biophotonics 6, 110-121. doi: 10.1002/jbio.2012 00146

Lewis, I. R., Daniel, N. W. Jr., Chaffin, N. C., and Griffiths, P. R. (1994). Raman spectrometry and neural networks for the classification of wood types. Spectochim. Acta A 50A, 1943-1958. doi: 10.1016/0584-8539(94)80207-6

Li, X., Ison, R. L., Kellaway, R. C., Stimson, C., Annison, G., and Joyce, D. C. (2011). Agronomic characteristics of annual Trifolium legumes and nutritive values as predicted by near-infrared reflectance (NIR) spectroscopy. Crop Pasture Sci. 62, 1078-1087. doi: 10.1071/Cp10158

Lu, S. E., Novak, J., Austin, F. W., Gu, G., Ellis, D., Kirk, M., et al. (2009). Occidiofungin, a unique antifungal glycopeptide produced by a strain of Burkholderia contaminans. Biochemistry 48, 8312-8321. doi: 10.1021/ Bi900814c

Lyubenova, L., Pongrac, P., Vogel-Mikuš, K., Mezek, G. K., Vavpetic, P., Grlj, N., et al. (2012). Localization and quantification of $\mathrm{Pb}$ and nutrients in Typha latifolia by micro-PIXE. Metallomics 4, 333-341. doi: 10.1039/C2mt00179a

Mazur, A. I., Monahan, J. L., Miljkovic, M., Laver, N., Diem, M., and Bird, B. (2013). Vibrational spectroscopic changes of B-lymphocytes upon activation. $J$ Biophotonics 6, 101-109. doi: 10.1002/jbio.201200136

McCann, M. C., Hammouri, M., Wilson, R. H., Belton, P., and Roberts, K. (1992). Fourier transform infrared microspectroscopy is a new way to look at plant cell walls. Plant Physiol. 100, 1940-1947. doi: 10.1104/pp.100.4.1940

Nascimento, J. M. P., and Dias, J. M. B. (2005). Vertex component analysis: a fast algorithm to unmix hyperspectral data. IEEE Trans. Geosci. Remote Sens. 43, 898-910. doi: 10.1109/Tgrs.2005.844293

Oliveira, L., Eutuguin, D., Cordeiro, N., and Silvestre, A. J. D. (2009). Structural characterization of stalk lignin from banana plant. Ind. Crops Prod. 29, 86-95. doi: 10.1016/j.indcrop.2008.04.012 doi: 10.1016/j.indcrop.2008.04.012

Pandey, K. K., and Vuorinen, T. (2008). UV resonance Raman spectroscopic study of photodegradation of hardwood and softwood lignins by UV laser. Holzforschung 62, 183-188. doi: 10.1515/HF.2008.046 
Perera, P. N., Schmidt, M., Chiang, V. L., Schuck, P. J., and Adams, P. D. (2012). Raman-spectroscopy-based noninvasive microanalysis of native lignin structure. Anal. Bioanal. Chem. 402, 983-987. doi: 10.1007/s00216-011-5518-x

Perera, P. N., Schmidt, M., Schuck, P. J., and Adams, P. D. (2011). Blind image analysis for the compositional and structural characterization of plant cell walls. Anal. Chim. Acta 702, 172-177. doi: 10.1016/j.aca.2011.06.021

Pu, Y. Q., Kosa, M., Kalluri, U. C., Tuskan, G. A., and Ragauskas, A. J. (2011) Challenges of the utilization of wood polymers: how can they be overcome? Appl. Microbiol. Biotechnol. 91, 1525-1536. doi: 10.1007/s00253-011-3350-Z

Ralph, J., Guillaumie, S., Grabber, J. H., Lapierre, C., and Barriere, Y. (2004). Genetic and molecular basis of grass cell-wall biosynthesis and degradability. III. Towards a forage grass ideotype. C. R. Biol. 327, 467-479. doi: 10.1016/j.crvi.2004.03.004

Ralph, J., Hatfield, R. D., Sederoff, R. R., and MacKay, J. J. (1998). Order and randomness in lignin and lignification: is a new paradigm for lignification required? Res. Summ. 39-41.

Richter, S., Mussig, J., and Gierlinger, N. (2011). Functional plant cell wall design revealed by the Raman imaging approach. Planta 233, 763-772. doi: $10.1007 / \mathrm{s} 00425-010-1338-\mathrm{z}$

Robinson, A. R., and Mansfield, S. D. (2009). Rapid analysis of poplar lignin monomer composition by a streamlined thioacidolysis procedure and nearinfrared reflectance-based prediction modeling. Plant J. 58, 706-714. doi: 10.1111/j.1365-313X.2009.03808.x

Ruel, K., Burlat, V., and Joseleau, J. P. (1999). Relationship between ultrastructural topochemistry of lignin and wood properties. IAWA J. 20, 203-211. doi: 10.1163/22941932-90000681

Shinzawa, H., Awa, K., Kanematsu, W., and Ozaki, Y. (2009). Multivariate data analysis for Raman spectroscopic imaging. J. Raman Spectrosc. 40, 1720-1725. doi: $10.1002 /$ jrs. 2525

Stewart, D., Yahiaoui, N., McDougall, G. J., Myton, K., Marque, C., Boudet, A. M., et al. (1997). Fourier-transform infrared and Raman spectroscopic evidence for the incorporation of cinnamaldehydes into the lignin of transgenic tobacco (Nicotiana tabacum L) plants with reduced expression of cinnamyl alcohol dehydrogenase. Planta 201, 311-318. doi: 10.1007/s004250050072

Studer, M. H., DeMartini, J. D., Davis, M. F., Sykes, R. W., Davison, B., Keller, M. et al. (2011). Lignin content in natural Populus variants affects sugar release. Proc. Natl. Acad. Sci. U.S.A. 108, 6300-6305. doi: 10.1073/pnas.1009252108

Sun, L., Simmons, B. A., and Singh, S. (2011a). Understanding tissue specific compositions of bioenergy feedstocks through hyperspectral Raman imaging. Biotechnol. Bioeng. 108, 286-295. doi: 10.1002/bit.22931
Sun, L., Varanasi, P., Yang, F., Loqué, D., Simmons, B. A., and Singh, S. (2011b). Rapid determination of syringyl: guaiacyl ratios using FTRaman spectroscopy. Biotechnol. Bioeng. 109, 647-656. doi: 10.1002/bit. 24348

Terashima, N., and Fukushima, K. (1988). Heterogeneity in formation of lignin - XI: an autoradiographic study of the heterogeneous formation and structure of pine lignin Wood Sci. Technol. 22, 259-270. doi: 10.1007/BF00 386021

Thomas, L. H., Forsyth, V. T., Sturcová, A., Kennedy, C. J., May, R. P., Altaner, C. M., et al. (2013). Structure of cellulose microfibrils in primary cell walls from collenchyma. Plant Physiol. 161, 465-476. doi: 10.1104/pp.112.206359

Vanholme, R., Demedts, B., Morreel, K., Ralph, J., and Boerjan, W. (2010). Lignin biosynthesis and structure. Plant Physiol. 153, 895-905. doi: $10.1104 /$ pp.110.155119

Weng, J. K., and Chapple, C. (2010). The origin and evolution of lignin biosynthesis. New Phytol. 187, 273-285. doi: 10.1111/j.1469-8137.2010.03327.x

Yoo, H. D., Kim, D., Paek, S. H., and Oh, S. E. (2012). Plant cell wall polysaccharides as potential resources for the development of novel prebiotics. Biomol. Ther. 20, 371-379. doi: 10.4062/biomolther.2012.20.4.371

Zhang, X., and Tauler, R. (2013). Application of multivariate curve resolution alternating least squares (MCR-ALS) to remote sensing hyperspectral imaging. Anal. Chim. Acta 762, 25-38. doi: 10.1016/j.aca.2012.11.043

Conflict of Interest Statement: The author declares that the research was conducted in the absence of any commercial or financial relationships that could be construed as a potential conflict of interest.

Received: 30 April 2014; accepted: 09 June 2014; published online: 30 June 2014. Citation: Gierlinger N (2014) Revealing changes in molecular composition of plant cell walls on the micron-level by Raman mapping and vertex component analysis (VCA). Front. Plant Sci. 5:306. doi: 10.3389/fpls.2014.00306

This article was submitted to Plant Biophysics and Modeling, a section of the journal Frontiers in Plant Science.

Copyright (c) 2014 Gierlinger. This is an open-access article distributed under the terms of the Creative Commons Attribution License (CC BY). The use, distribution or reproduction in other forums is permitted, provided the original author(s) or licensor are credited and that the original publication in this journal is cited, in accordance with accepted academic practice. No use, distribution or reproduction is permitted which does not comply with these terms. 